\title{
Two-step process for preparation of oligosaccharide propionates and acrylates using lipase and Cyclodextrin Glycosyl Transferase (CGTase)
}

\author{
Bianca T Ayres ${ }^{1}$, Gustavo P Valença' ${ }^{1}$, Telma T Franco $^{1}$ and Patrick Adlercreutz ${ }^{2 *}$
}

\begin{abstract}
Background: Oligosaccharide esters are attractive candidates for applications as surfactants, hydrogels and other materials, but direct enzymatic acylation is difficult with carbohydrates longer than disaccharides.

Results: A combination of one lipase-catalyzed step and one transglycosylation step catalyzed by a cyclodextrin glycosyl transferase (CGTase) was used to synthesize oligosaccharide esters. The conversion of glucose and maltose with vinyl propionate catalyzed by Candida antarctica lipase B (Novozym 435) in dioxane proceeded to full conversion to mixtures of mono and diesters. When ethyl acrylate was used as acyl donor, mono and diesters were formed, but full conversion was not reached. The CGTase catalyzed reactions between the glucose and maltose esters and a-cyclodextrin were carried out in water. In the initial phase, addition of the glucose residues of the cyclodextrin to the ester substrate occurred (coupling reaction), followed by disproportionation reactions yielding a range of oligosaccharide esters with varying chain length. The monoesters were efficient acceptors in the CGTase-catalyzed reactions, while the diesters were not converted to a significant extent. As a consequence, the glucose propionate which contained large amounts of diesters was converted to $40 \%$ conversion while the maltose propionate which contained mainly monoesters was converted to $86 \%$ conversion.
\end{abstract}

Conclusions: A two-step enzymatic process for preparation of oligosaccharide esters has been developed. Oligosaccharide propionates were produced in high yield with a total reaction time of $5 \mathrm{~h}$. The double bond of the acrylate moiety reduced the reaction rate of the lipase catalyzed transesterification, but in both cases, the CGTase efficiently converted the monoesters to oligosaccharide esters.

Keywords: Maltooligosaccharide, Propionate, Acrylate, Sugar ester, CGTase, Lipase

\section{Background}

The change of chemical industry to renewable feedstocks provides new opportunities for biocatalysis as a "green" tool in the sustainable production of novel materials. Typical examples are carbohydrate esters, some of which are already used as surfactants. If a wider range of carbohydrate esters can be produced, the range of applications can be widened. Generally, this type of products has low toxicity and good biodegradability.

\footnotetext{
* Correspondence: Patrick.Adlercreutz@biotek.lu.se

${ }^{2}$ Biotechnology, Lund University, P.O. Box 124, SE 22200 Lund, Sweden Full list of author information is available at the end of the article
}

In this study, possibilities for enzymatic production of oligosaccharide esters are explored, using propionates and acrylates as examples. Acrylates are of special interest because of the possibilities for further reactions, for example polymerization. On the other hand, because of their structure and reactivity acrylates may cause complications in the reactions, and propionates are therefore studied as well to show how the reactions work with a saturated carboxylic acid with the same length. Acrylates and propionates of carbohydrates have been described in the literature with a maximum of two monosaccharidic residues [1-3]. The most widely used synthesis strategy is regioselective (trans)esterification catalyzed by lipases, 
under mild conditions. The reaction media are apolar organic solvent with low water content to avoid hydrolytic side reactions. While successful enzymatic synthesis of esters of mono and disaccharides has been reported in a large number of cases [4-7], esterification of longer carbohydrates is very difficult to achieve [7]. However, acylation of maltotriose was achieved using vinyl esters as acyl donors and 2-methyl-2-butanol/dimethyl sulfoxide as solvent [8]. Enzymatic esterification of starch has been reported, but recent detailed studies have shown that the analysis methods used in most previous studies are not reliable [9]. Using proper analytical methods it has been shown that acylation of starch can indeed be carried out, but the degree of modification was below 0.02 [9].

The lipase-catalyzed transesterification of monosaccharides with vinyl acrylate, followed by chemical polymerization, has successfully been used to prepare poly (acrylate)-based hydrogels [1]. In this study we aimed for products with higher carbohydrate content, and a two step enzymatic process to oligosaccharide esters was developed. The strategy was to carry out a lipase-catalysed esterification between glucose or maltose, and then elongate the carbohydrate part using a transglycosylation reaction catalyzed by a cyclodextrin glycosyl transferase (CGTase, E.C.2.4.1.19) (Figure 1). CGTases are mainly used for the production of cyclodextrins from starch, but they can catalyze other reactions as well. Their hydrolytic activity is normally quite low, but they can efficiently catalyze disproportionation reactions between linear carbohydrates. In addition, they can catalyze coupling reactions, in which the glucose residues of a cyclodextrin are added to an acceptor, which normally is a linear maltooligosaccharide. However, it has been shown that also derivatized carbohydrates, such as sugar esters and alkyl glycosides can function as acceptors in CGTase-catalyzed coupling reactions [10-12]. Often, the initial coupling reaction is followed by disproportionation reactions to give a range of products with varying chain length.

In this study, a screening of lipases and organic solvents was carried out to find good conditions for the esterification of glucose and maltose. The carbohydrate esters produced in these reactions were isolated and used as substrates together with $\alpha$-cyclodextrin in the CGTase catalyzed reactions in aqueous solution, to produce oligosaccharide esters, which were the target products of this study.

\section{Results and discussion}

Lipase-catalysed transesterification of glucose and maltose Screening of lipases and organic solvents

In order to achieve acylation of carbohydrates using lipase-catalyzed transesterification reactions, predominantly organic reaction media must be used to minimize competing hydrolysis reactions. A range of organic solvents and immobilized lipases were evaluated for the transesterification between glucose or maltose and ethyl acrylate. Some lipases did not express significant catalytic activity under the conditions used (Table 1). The commercial immobilized preparation containing $T$. lanuginosus lipase produced significant amounts of products and the very best activity was observed for $C$. antarctica lipase B, either in the commercially available form Novozym 435 or immobilized by adsorption on MP1000. This agrees with previous observations that $C$. antarctica lipase B works well in organic media with low water content and is able to convert a wide range of substrates [13,14].

Carbohydrate acylation was observed in all the solvents studied. The largest amounts of products were formed in dioxane, which was thus chosen for further studies. Novozym 435 was selected as catalyst because of slightly larger amounts of products compared to the MP1000 preparation.

\section{Influence of the acyl donor}

Sugar esters were synthesised in dioxane from ethyl acrylate or vinyl propionate and either glucose or maltose, using Novozym 435 as catalyst. TLC analysis of the reaction mixture and controls without enzyme, revealed complete enzymatic conversion of the carbohydrate when vinyl propionate was the acyl donor. The esterification of glucose

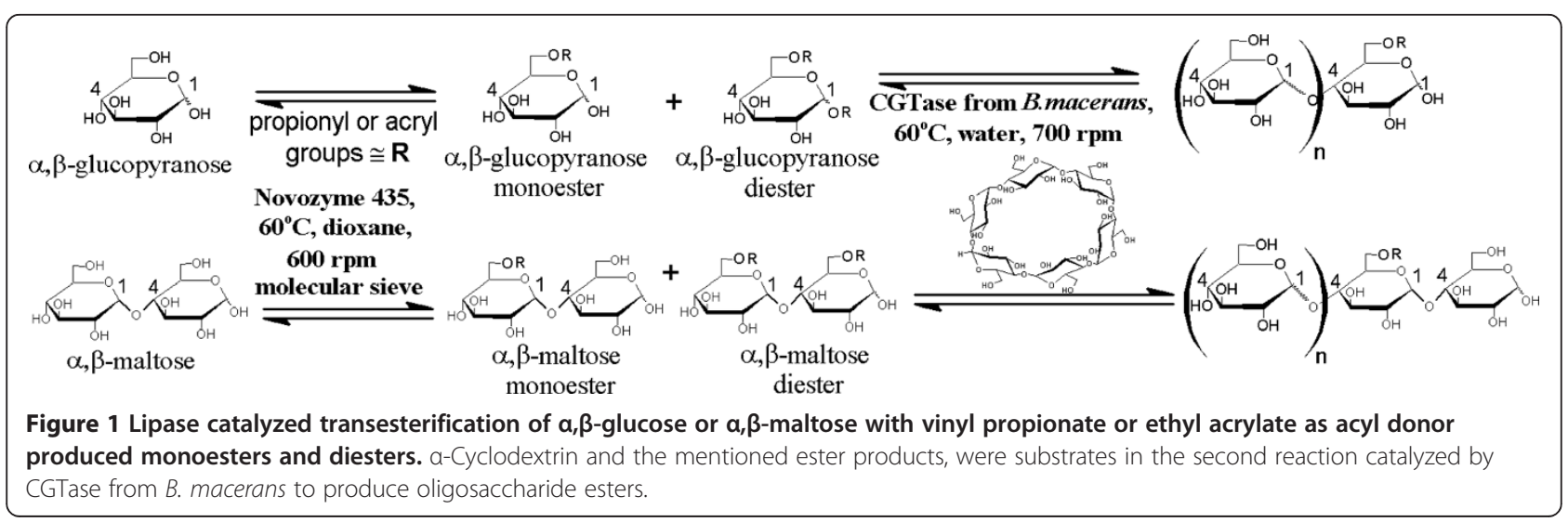


Table 1 Screening of organic solvent and immobilized lipases for transesterification of ethyl acrylate with glucose (G1) or maltose (G2)

\begin{tabular}{|c|c|c|c|c|c|c|c|}
\hline & & $\begin{array}{c}\text { Dioxane } \\
(-1.1)\end{array}$ & $\begin{array}{c}\text { Acetonitrile } \\
(-0.36)\end{array}$ & $\begin{array}{c}\text { Acetone } \\
(-0.3)\end{array}$ & $\begin{array}{c}\text { Tetrahydrofurane } \\
(0.49)\end{array}$ & $\begin{array}{c}\text { Tert-butylalcohol } \\
(0.83)\end{array}$ & $\begin{array}{c}\text { Tert-amylalcohol } \\
(1.4)\end{array}$ \\
\hline \multirow[t]{2}{*}{ C. antarctica (N435) } & G1 & ++++ & +++ & ++++ & ++++ & +++ & +++ \\
\hline & G2 & ++++ & + & ++++ & +++ & + & ++ \\
\hline \multirow[t]{2}{*}{ C. antarctica (MP1000) } & G1 & ++++ & ++ & ++ & ++++ & +++ & +++ \\
\hline & G2 & ++++ & ++ & ++ & - & ++ & ++ \\
\hline \multirow[t]{2}{*}{ T. lanuginosa (Lipozyme TL IM) } & G1 & ++ & ++ & + & ++ & ++ & +++ \\
\hline & G2 & ++ & - & + & +++ & + & ++ \\
\hline \multirow[t]{2}{*}{ T. lanuginosa (MP1000) } & G1 & - & - & - & - & - & - \\
\hline & G2 & - & - & - & - & - & - \\
\hline \multirow[t]{2}{*}{ M. miehei (MP1000) } & G1 & + & - & - & - & + & - \\
\hline & G2 & - & - & - & - & - & - \\
\hline \multirow[t]{2}{*}{ C. rugosa (MP1000) } & G1 & - & - & - & - & - & - \\
\hline & G2 & - & - & - & - & - & - \\
\hline
\end{tabular}

Product formation is expressed using the following scale to describe the color intensity of the product spots on TLC: (-) not detected; (+) weak; $(++)$ intermediate; $(+++)$ strong; $(++++)$ very strong.

with vinyl propionate produced considerable amounts of both mono and diesters, while the corresponding reaction with maltose produced mainly monoesters.

The esterification of maltose with ethyl acrylate as acyl donor produced monoester as main product as well, but considerable amounts of maltose always remained in the reaction mixtures. Different combinations of excess of acyl donor, reduced initial sugar content, increase of lipase load and addition of molecular sieves ( $3 \AA$ ) were evaluated, but full conversion was not achieved.

The differences in conversion when the two acyl donors were used can be due to multiple reasons. Vinyl esters are often used to achieve high conversions in transesterification reactions, which is facilitated by the fact that the leaving group, vinyl alcohol, is not stable, but is spontaneously converted to acetaldehyde, thereby making the acylation reaction virtually irreversible [15]. Ethyl esters can be used in a similar way if the ethanol formed is evaporated [16], but this approach is less efficient than the use of vinyl esters. Furthermore, the double bound in the acrylate moiety often makes it less reactive in lipase-catalyzed conversions $[17,18]$.

The transesterification reactions were studied in more detail, using reversed phase HPLC for analysis. In these analyses, glucose and maltose in solution were quantified as well. Their solubility in organic solvents is low. The solubility of glucose and maltose in dioxane at $60^{\circ} \mathrm{C}$ were $19.4 \mathrm{mM}$ and $7.3 \mathrm{mM}$, respectively. The addition of the acyl donor $(250 \mathrm{mM})$ led to higher sugar concentration in the liquid phase (glucose and maltose respectively): with vinyl propionate, $37.2 \mathrm{mM}$ and $14 \mathrm{mM}$; and with ethyl acrylate, $45 \mathrm{mM}$ and $20.5 \mathrm{mM}$. After a couple of hours of reaction, the liquid phase was depleted of the underivatized carbohydrates (Figure 2). The introduction of acyl groups in the carbohydrates caused an increase in retention time in the HPLC analysis. Mono and
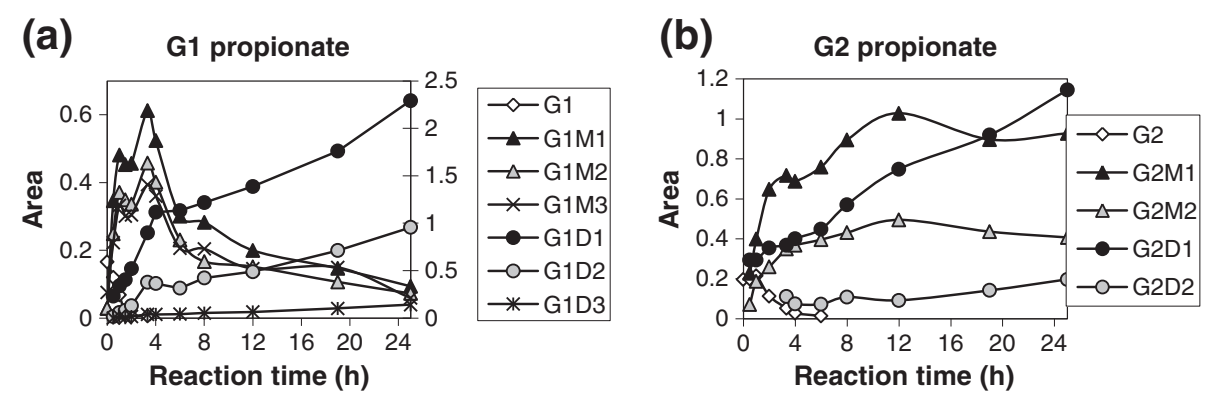

Figure 2 Enzymatic transesterification of $50 \mathrm{mM} \mathrm{G1}$ (a) or G2 (b) with $250 \mathrm{mM}$ vinyl propionate by N435 in dioxane at $60^{\circ} \mathrm{C}$. GxMi are monoesters, GxDi are diesters, $x$ is the number of glucose units and $i$ is an isomer of the ester. In Figure 2a, the right $y$-axis is used for the G1 diesters and the left one for the other substances. 
diesters eluted in separate groups and peaks for different isomers were observed. In the acylation of glucose with vinyl propionate, three different monoesters were detected. Their exact identity was not deduced, but based on literature reports one of them is expected to be 6-Opropionyl glucose [19]. Due to lack of standards, quantification was carried out only based on peak area in the chromatograms. With the type of detector used, the peak areas roughly correlate with the mass of the products. All the monoesters reached maximal concentrations after about 4 hours of reaction. Three diester products were detected and their concentrations increased continuously during the course of reaction. It has previously been reported that the main product in the CALBcatalyzed acylation of maltose is $6^{\prime}$-O-propionyl maltose [20], so this is expected to be one of the monoesters. The reaction between maltose and vinyl propionate followed a similar time course and produced two monoesters and two diesters. In this case, the maximal concentrations of monoesters were reached after longer reaction time, about 12 hours. This might be due to a slower reaction caused by the lower solubility of maltose in the reaction medium.

The transesterification reactions with ethyl acrylate as acyl donor produced lower conversion. In the acrylation of glucose, two monoesters were observed, while the acrylation of maltose produced one monoester and one diester (results not shown). The maximal concentration of glucose monoester was achieved after 4 hours while the maximum for maltose monoester was observed after 12 hours, as in the case with vinyl propionate as acyl donor.

\section{Elongation of the carbohydrate part of sugar esters by CGTase}

In order to obtain acylated oligosaccharides, the glucose and maltose esters produced in the lipase-catalyzed reactions were glycosylated using $\alpha$-cyclodextrin as glycosyl donor and CGTase as catalyst. During the initial phase of these reactions, coupling between $\alpha$-cyclodextrin and the carbohydrate esters is expected to be the dominating reaction. Since underivatized, linear saccharides are expected to be better acceptors than the esters, it was important that the carbohydrate esters did not contain any remaining glucose or maltose. Since the formation of propionates continued to full conversion, the products were used directly while the carbohydrate acrylates were purified by flash chromatography to remove remaining underivatized carbohydrates.

Reversed phase HPLC analysis showed that the glucose monopropionates were converted in the CGTasecatalyzed reactions, while the glucose diesters remained unchanged (Figure 3). In the conversions of glucose and maltose acrylates, lower substrate concentrations were used, but detailed inspection of the chromatograms indicated that the monoesters were converted in this case as well (Figure 4).

After the CGTase-catalyzed conversions, new peaks appeared before $\alpha$-cyclodextrin in the chromatograms, but they were not well resolved (Figures 3 and 4). This is not surprising since the product can be expected to be a rather complex mixture of oligosaccharides of different chain length, having acyl groups in different positions. In order to further analyse the products, HPAEC-PAD was

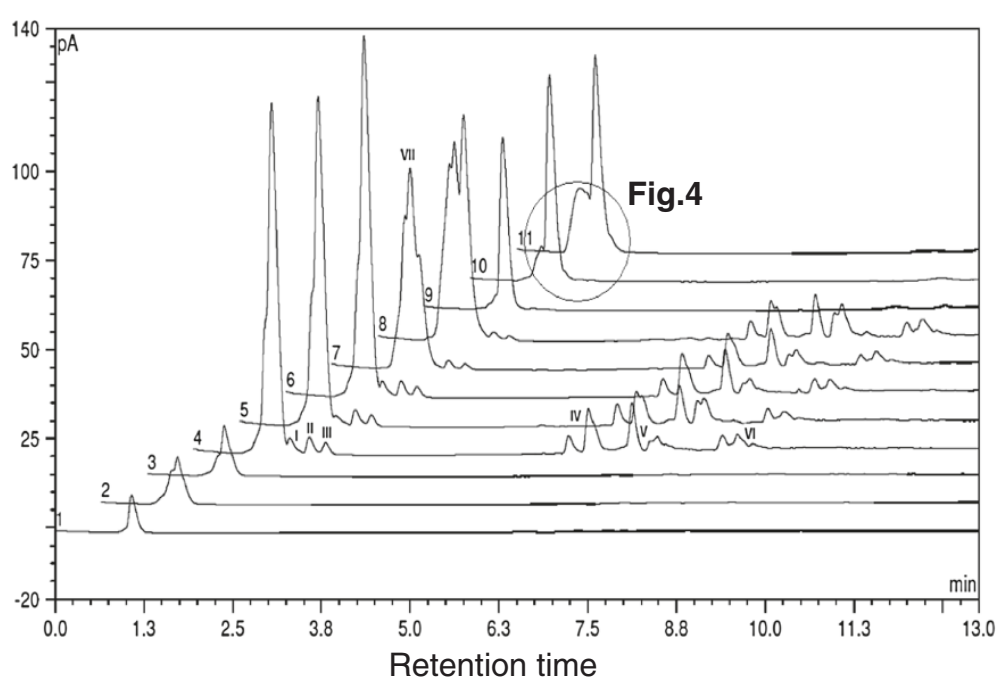

Figure 3 Reversed phase HPLC analysis of reaction mixtures from transglycosylation reactions. Chromatograms 1,2 and 3 were the blank medium with only a-CD (205 mM) and CGTase at 0 h, 2 h and 12 h, respectively (no acceptor). Chromatograms 4 and 5 contained a-CD, 410 mM as initial concentration and G1P (I, II and III- monopropionate isomers - IV, V and VI - dipropionate isomers) without CGTase at $0 \mathrm{~h}$ and $24 \mathrm{~h}$. Chromatograms 6, 7 and 8 contained G1P, a-CD (410 mM) and CGTase at 0 h, 2 h and 12 h. Chromatograms 9,10 and 11 from a reaction containing a-CD (410 mM), G2A (VIII and IX) and CGTase at 0 h, 8 min and $2 \mathrm{~h}$ of reaction time. 


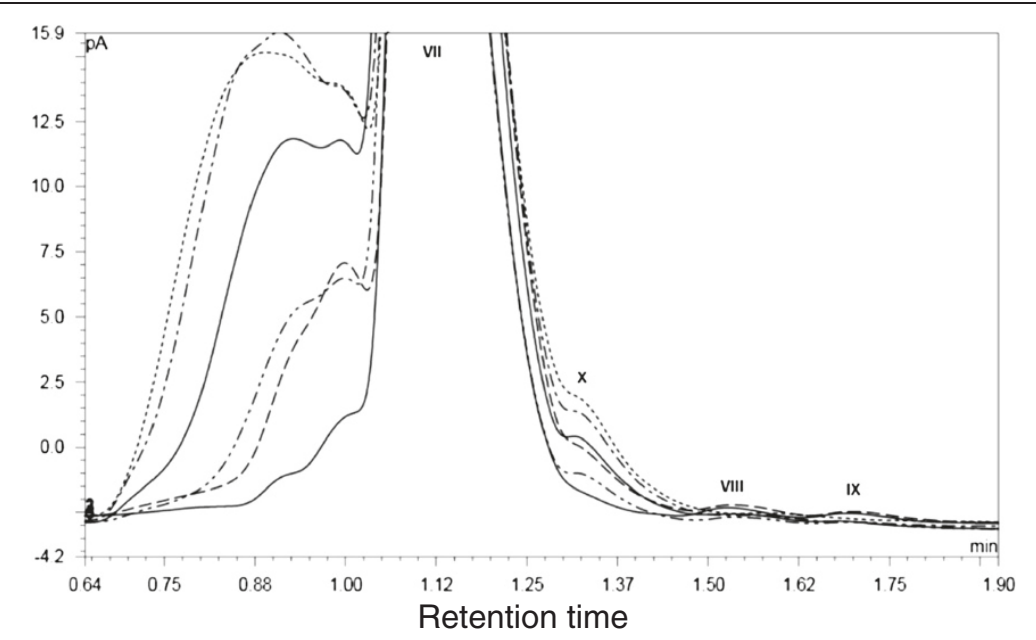

Figure 4 Reversed phase HPLC chromatogram of reaction mixtures from CGTase-catalyzed transglycosylation of G2A (VIII and IX) with a-CD (VII) after $0 \mathrm{~min}(-), 8 \mathrm{~min}(--), 15 \mathrm{~min}(----), 30 \mathrm{~min}(-), 1 \mathrm{~h} \mathrm{(-} \mathrm{-} \mathrm{-)} \mathrm{and} 2 \mathrm{~h} \mathrm{(-} \mathrm{-} \mathrm{-)} \mathrm{of} \mathrm{reaction} \mathrm{time.}$

used. This methodology is quite powerful in the separation and quantification of carbohydrates. Since the eluent used is strongly basic, ester bonds are hydrolysed. This means that the propionate and acrylate groups were removed and the remaining oligosaccharides were easy to quantify. In the reaction between $\alpha$-cyclodextrin and glucose propionate, analysis before reaction showed mainly $\alpha$-cyclodextrin and glucose (originating from glucose monopropionates and glucose dipropionates) (Additional file 1: Table S1). After 1 hour reaction both these peaks had decreased considerably and the largest new peaks were those of maltoheptaose and maltotridecanose which are expected to originate from products obtained in the coupling reaction between the glucose propionate and one or two $\alpha$ cyclodextrin molecules, respectively. In addition, all other maltooligosaccharides with between 2 and 14 glucose residues were observed, which shows that already at this time, disproportionation reactions had occurred to a large extent. At extended incubation, further disproportionation reactions occurred. After 1 hour reaction, $40.5 \%$ of the glucose propionate substrate had been converted (Table 2), and further reaction did not convert more of this substrate

Table 2 CGTase catalyzed transglycosylation between a-CD (donor substrate) and propionates (mixtures of mono and diesters) of glucose and maltose

\begin{tabular}{lccc}
\hline & & \multicolumn{2}{c}{ Conversion (\%) } \\
\cline { 3 - 4 } & & Donor & Acceptor \\
\hline R-G1P & $1 \mathrm{~h}$ & 75.5 & 40.5 \\
C-G1P & $24 \mathrm{~h}$ & 17.3 & - \\
R-G2P & $1 \mathrm{~h}$ & 55.2 & 86.3 \\
C-G2P & $24 \mathrm{~h}$ & 14.6 & - \\
\hline
\end{tabular}

R: with enzyme; C: without enzyme.
(Additional file 1: Table S1). Based on the reversed phase HPLC analysis, it can be concluded that a major part of the unreacted glucose ester substrate consists of glucose diesters. In the corresponding reaction between $\alpha$ cyclodextrin and maltose propionate, $86.3 \%$ of the maltose propionate had been converted after 1 hour reaction. The reason for the higher conversion compared to the case with glucose propionate is probably that the maltose propionate contained a larger proportion of monoesters than the glucose propionate (Figure 2). In the absence of enzyme, no conversion of the carbohydrate esters was observed and much less conversion of $\alpha$-cyclodextrin, even after 24 hours incubation (Table 2). It is known that glucose can act as acceptor in coupling reactions catalyzed by CGTase from $B$. macerans and that maltose was the best of all acceptors tested [21].

The results of the present study show that also monoesters of glucose and maltose can function as acceptors in these reactions while diesters cannot. CGTase acts in $\alpha-1,4$ bonds of saccharides. Possible reasons for lack of reactivity of the diesters are that the 4-hydroxyl group might have been esterified in the diesters or that ester groups in other positions caused steric hindrance.

The results obtained show that the presented two-step process can be used to produce oligosaccharide monoesters. Further optimization can probably increase the reaction efficiency. Furthermore, it might be possible to find alternative enzymes and/or alternative reaction conditions to produce oligosaccharide esters containing more than one ester group.

\section{Experimental}

Materials

Ethyl acrylate, vinyl propionate, tert-butanol, dioxane, glucose, maltose and lipases from $C$. antarctica and 
T. lanuginosus were purchased from Sigma (Steinheim, Germany), $\alpha$-cyclodextrin from Wacker Chemie AG (Burghausen, Germany), immobilized lipase from C. antarctica (Novozym 435) was obtained from Novozymes (Bagsvaerd, Denmark) and CGTase from $B$. macerans was obtained from Amano Enzyme Europe Ltd. (Nagoya, Japan). All other chemicals were from VWR International (Stockholm, Sweden).

\section{Screening of lipases, support and organic solvents}

The screening of the lipases was studied for enzymatic transesterification between equimolar mixtures of glucose or maltose $(0.5 \mathrm{mmol}$ of glucose units) and ethyl acrylate in $0.6 \mathrm{~mL}$ of organic solvent (acetone, acetonitrile, dioxane, tert-amyl alcohol, tert-butyl alcohol or tetrahydrofurane (THF)). The weight of immobilized lipase added corresponded to the hydrolytic activity of $15 \mu \mathrm{mol}^{*} \mathrm{~min}^{-1} \mathrm{ml}^{-1}$ for $\mathrm{pNPB}$. For the commercially available immobilized lipases N435 and TL IM, the amount added was $22.5 \mathrm{mg}$.

Systems with immobilized $R$. miehei or C. rugosa lipases on MP1000 and all experiments in acetone $\left(\mathrm{bp}=56^{\circ} \mathrm{C}\right.$ ) and THF $\left(\mathrm{bp}=66^{\circ} \mathrm{C}\right)$ were carried out at $50^{\circ} \mathrm{C}$ and $700 \mathrm{rpm}$ in a ThermoMixer apparatus (HLC-Biotech, Model MKR 13, Bovenden, Germany). Meanwhile, the lipases from C. antarctica and T. lanuginosus in the other organic solvents were investigated at $60^{\circ} \mathrm{C}$. The reactors were $2 \mathrm{~mL}$ screw-capped vials with rubber septum.

\section{Transesterification by lipase}

Transesterification of vinyl propionate (molar ratio ester: sugar 5:1) with either glucose or maltose $(50 \mathrm{mM})$ was catalysed by Novozym $435\left(22 \mathrm{mg} \mathrm{mL}^{-1}\right)$ in the presence of $100 \mathrm{mg} \mathrm{mL}^{-1}$ of molecular sieves $(3 \AA)$ in $1 \mathrm{~mL}$ of dioxane. The reactions carried out in $2 \mathrm{~mL}$ screw-capped vials with septum incubated in the ThermoMixer at $60^{\circ} \mathrm{C}$ and $700 \mathrm{rpm}$. The samples were analyzed by TLC and HPLC.

Transesterification of ethyl acrylate (molar ratio ester: sugar $5: 1)$ with either glucose or maltose ( 25 or $50 \mathrm{mM}$ ) was catalysed by Novozym $435\left(22 \mathrm{mg} \mathrm{mL}^{-1}\right)$ in the presence of $100 \mathrm{mg} \mathrm{mL}^{-1}$ of molecular sieve $(3 \AA)$ in $1 \mathrm{~mL}$ dioxane. The reactions carried out in $2 \mathrm{~mL}$ screwcapped vial with septum incubated at $60^{\circ} \mathrm{C}$ and $700 \mathrm{rpm}$ in the ThermoMixer.

TLC and HPLC analysis monitored the reactions. Filtration and evaporation under vacuum removed lipase and the organic solvent, respectively. Maltose acrylate was purified by flash chromatography to eliminate the unreacted maltose.

\section{Transglycosylation by CGTase}

The transglycosylation reactions were performed in a reaction mixture consisting of either $1 \mathrm{~mL}$ (propionates) or
$0.2 \mathrm{~mL}$ (acrylates) of $10 \mathrm{mM}$ sodium citrate buffer, $\mathrm{pH} 5.2$, containing either sugar propionate $(4 \% \mathrm{w} / \mathrm{v})$ or sugar acrylate $(4 \% \mathrm{w} / \mathrm{v})$ as the acceptor substrate, $\alpha$-cyclodextrin (molar ratio 1:4) as the glycosyl donor and $\mathrm{CaCl}_{2}(5 \mathrm{mM})$. The reaction mixture was incubated at $60^{\circ} \mathrm{C}$ in the ThermoMixer mentioned above at $700 \mathrm{rpm}$. The reactions were carried out in $2 \mathrm{~mL}$ screw-capped vials with septum in case of acrylation system and $4.5 \mathrm{~mL}$ screw-capped vials for propionate conversion using CGTase from B.macerans $\left(175 \mu \mathrm{g} \mathrm{mL} \mathrm{m}^{-1}\right)$ as catalyst and the reaction progress was monitored for $24 \mathrm{~h}$. Samples were withdrawn and heat arrested in a boiling water bath for $2 \mathrm{~min}$. The samples were divided for two independent dilutions: for analysis on HPLC (10-fold with MeCN:water 50:50 v/v) and HPAEC-PAD (10.000-fold with buffer).

\section{Immobilization of lipases on MP1000}

Solutions of lipases from C. antarctica, T. lanuginosus, $R$. miehei or C. rugosa in phosphate buffer $50 \mathrm{mM}$ (pH 7.0) were prepared according to Gitlesen et al. [22]. The support MP1000 (particle size $200 \mu \mathrm{m}$ ) was prewetted with ethanol and was mixed with lipase solution, incubated for $1 \mathrm{~h}$, filtrated, washed three times with buffer and then dried in a desiccator overnight in a Petri-dish covered with aluminium foil. The Bradford method was used for protein determination.

\section{Lipase activity assay}

The hydrolytic activity of the immobilized lipase was measured through a spectrophotometric assay based on the hydrolysis of $p$-nitrophenyl butyrate (pNPB). The basic form of $p$-nitrophenol absorbs strongly at $400 \mathrm{~nm}$ and thus the absorbance increase at this wavelength was used for reaction rate measurement. The extinction coefficient of $p$-nitrophenol was $16000 \mathrm{M}^{-1} \mathrm{~cm}^{-1}$.

\section{Thin layer chromatography}

Preliminary transesterification reactions were followed by analytical thin layer chromatography (TLC) on silica gel 60 plates using acetonitrile: ethyl acetate: propanol: water $(85: 20: 50: 50 \mathrm{v} / \mathrm{v} / \mathrm{v} / \mathrm{v})$ for the separation of glycosides and sugars. Spots were visualized by spray of $5 \%$ $\mathrm{H}_{2} \mathrm{SO}_{4}$ in ethanolic solution, followed by heating at $120^{\circ} \mathrm{C}$ for $10 \mathrm{~min}$.

\section{High performance liquid chromatography (HPLC)}

A C18 column $(2.1 \mathrm{~mm} \times 150 \mathrm{~mm}, 2 \mu \mathrm{m}, 120 \AA$, Dionex $)$ was used for the separation of the glycosides coupled using a Dionex Ultimate 3000 HPLC system coupling with a Corona $^{\mathrm{Tm}}$ Charged Aerosol Detector (CAD) from ESA Biosciences and a variable wavelength UV-visible detector. The mobile phase employed was $95 \%$ of MilliQ water containing $0.1 \%$ of acetic acid (A) and acetonitrile (B); the flow rate was $0.4 \mathrm{~mL} \mathrm{~min}^{-1}$. The program was as follows: 
from $95 \% \mathrm{~A}$ to $85 \% \mathrm{~A}$ in $3 \mathrm{~min}$, from $85 \% \mathrm{~A}$ to $35 \% \mathrm{~A}$ in $7 \mathrm{~min}$, back to $95 \% \mathrm{~A}$ in $1 \mathrm{~min}$ and equilibration at the initial conditions for the next $4 \mathrm{~min}$. The UV-visible detector was operated at $200 \mathrm{~nm}$ and $250 \mathrm{~nm}$.

\section{HPAEC-PAD}

The HPAEC-PAD analysis was performed on a DIONEX ISC3000 system (Sunnyvale, CA, USA) including pump, detector and autosampler. A CarboPac PA200 column with guard column was used at $30^{\circ} \mathrm{C}$ and flow rate of $0.5 \mathrm{ml} / \mathrm{min}$. The injection volume was $10 \mu \mathrm{l}$. Three eluents were prepared in plastic bottles that were carefully purged using helium. The eluents consisted of water (A), $400 \mathrm{mM}$ sodium acetate containing $200 \mathrm{mM} \mathrm{NaOH}$ (B) and $200 \mathrm{mM} \mathrm{NaOH}(\mathrm{C})$. The oligosaccharides were eluted using the gradient in $30 \mathrm{~min}$ : 50\% to $0 \% \mathrm{C}$ and $0 \%$ to $50 \%$ B. The initial condition was equilibrated in 5 min between the injections.

\section{Conclusions}

Maltooligosaccharide esters were synthesized by a combination of a transesterification catalysed by a lipase in an organic solvent and a transglycosylation with $\alpha$-cyclodextrin as glycosyl donor catalysed by CGTase in water. Novozym 435 was the most efficient lipase and dioxane was the best solvent for the transesterification reaction. Vinyl propionate was a very efficient acyl donor, leading to full conversion of both glucose and maltose to mixtures of mono and diesters. Ethyl acrylate also worked as acyl donor but full conversion was not reached. Monoesters of both glucose and maltose worked well as acceptors in the CGTase-catalyzed reactions, while diesters were not converted to a significant extent. The two-step approach presented in this paper is thus suited for the preparation of oligosaccharide monoesters.

\section{Additional file}

Additional file 1: Table S1. HPAEC-PAD analysis of reaction mixtures from tranglycosylation of G1 propionate or G2 propionate with $410 \mathrm{mM}$ of a-CD with $175 \mu \mathrm{g} / \mathrm{ml}$ of CGTase, $60^{\circ} \mathrm{C}, 600 \mathrm{rpm}$ and sodium-citrate buffer, pH 5.2. During the analysis conditions used, ester bonds were hydrolysed, providing glucose, maltose and maltooligosaccharides for quantification.

\section{Abbreviations}

G1P: Glucose propionate; G2P: Maltose propionate; HPAEC-PAD: High performance anion exchange chromatography-pulsed amperometric detection.

Competing interests

The authors declare that they have no competing interests.

\section{Authors' contributions}

BA carried out the experimental work and wrote the first draft of the manuscript. GV and TF conceived the reaction investigation aiming acrylates of maltooligosaccharides. PA coordinated the work and helped to write the manuscript. All authors read and approved the final manuscript.

\section{Acknowledgements}

This project was supported by the Brazilian funding agency FAPESP (Project $n^{\circ}$ 2012/06859-0) and The Swedish Research Council Formas (grant $\left.n^{\circ} 213-2012-820\right)(P A)$

\section{Author details}

${ }^{1}$ Chemical Processes Department, School of Chemical Engineering, University of Campinas, 13083-852 Campinas, São Paulo, Brazil. Biotechnology, Lund University, P.O. Box 124, SE 22200 Lund, Sweden.

Received: 19 December 2013 Accepted: 25 February 2014

Published: 13 March 2014

\section{References}

1. Martin BD, Ampofo SA, Linhardt RJ, Dordick JS: Biocatalytic synthesis of sugar-containing poly(acrylate)-based hydrogels. Macromolecules 1992 25:7081-7085

2. Patil NS, Li YZ, Rethwisch DG, Dordick JS: Sucrose diacrylate: a unique chemically and biologically degradable crosslinker for polymeric hydrogels. J Polymer Sci Part a-Polymer Chem 1997, 35:2221-2229

3. Croitoru R, Fitigau F, van den Broek LAM, Frissen AE, Davidescu CM, Boeriu CG, Peter F: Biocatalytic acylation of sugar alcohols by 3-(4-hydroxyphenyl) propionic acid. Process Biochem 2012, 47:1894-1902

4. Ljunger $G$, Adlercreutz P, Mattiasson B: Lipase catalyzed acylation of glucose. Biotechnol Lett 1994, 16:1167-1172.

5. Cao L, Fischer A, Bornscheuer UT, Schmid RD: Lipase-catalyzed solid phase synthesis of sugar fatty acid esters. Biocatal Biotransform 1997, 14:269-283.

6. Gumel AM, Annuar MSM, Heidelberg T, Chisti Y: Lipase mediated synthesis of sugar fatty acid esters. Process Biochem (Amsterdam, Neth) 2011 46:2079-2090.

7. Degn P, Pedersen LH, Duus JO, Zimmermann W: Lipase-catalysed synthesis of glucose fatty acid esters in tert-butanol. Biotechnol Lett 1999, 21:275-280

8. Ferrer $M$, Cruces MA, Plou FJ, Bernabe M, Ballesteros A: A simple procedure for the regioselective synthesis of fatty acid esters of maltose, leucrose, maltotriose and n-dodecyl maltosides. Tetrahedron 2000, 56:4053-4061.

9. Alissandratos A, Baudendistel N, Flitsch SL, Hauer B, Halling PJ: Lipase-catalysed acylation of starch and determination of the degree of substitution by methanolysis and GC. BMC Biotechnol 2010, 10:82.

10. Okada K, Zhao H, Izumi M, Nakajima S, Baba N: Glucosylation of sucrose laurate with cyclodextrin glucanotransferase. Biosci Biotechnol Biochem 2007, 71:826-829.

11. Svensson D, Ulvenlund S, Adlercreutz P: Enzymatic route to alkyl glycosides having oligomeric head groups. Green Chem 2009, 11:1222-1226.

12. Svensson D, Ulvenlund S, Adlercreutz P: Efficient synthesis of a long carbohydrate chain alkyl glycoside catalyzed by Cyclodextrin Glycosyltransferase (CGTase). Biotechnol Bioeng 2009, 104:854-861.

13. Anderson EM, Karin M, Kirk O: One biocatalyst - many applications: the use of Candida antarctica B-lipase in organic synthesis. Biocatal Biotransform 1998, 16:181-204.

14. Nordblad M, Adlercreutz P: Efficient enzymatic acrylation through transesterification at controlled water activity. Biotechnol Bioeng 2008, 99:1518-1524.

15. Hanefeld U: Reagents for (ir) reversible enzymatic acylations. Org Biomol Chem 2003, 1:2405-2415.

16. Ohrner N, Martinelle M, Mattson A, Norin T, Hult K: Displacement of the equilibrium in lipase catalyzed transesterification in ethyl octanoate by continuous evaporation of ethanol. Biotechnol Lett 1992, 14:263-268.

17. Nordblad M, Adlercreutz P: Effects of acid concentration and solvent choice on enzymatic acrylation by Candida antarctica lipase B. J Biotechnol 2008, 133:127-133.

18. Syren $\mathrm{PO}$, Hult K: Substrate conformations set the rate of enzymatic acrylation by lipases. ChemBioChem 2010, 11:802-810.

19. Yan YC, Bornscheuer UT, Stadler G, Lutz-Wahl S, Otto RT, Reuss M, Schmid $\mathrm{RD}$ : Regioselective lipase-catalyzed synthesis of glucose ester on a preparative scale. Eur J Lipid Sci Technol 2001, 103:583-587. 
20. Woudenberg-van Oosterom M, van Rantwijk F, Sheldon RA: Regioselective acylation of disaccharides in tert-butyl alcohol catalyzed by Candida antarctica lipase. Biotechnol Bioeng 1996, 49:328-333.

21. Vetter $D$, Thorn W: Chain length specificity of cyclodextrin glycosyltransferase. Starch/Stärke 1992, 44:229-233.

22. Gitlesen T, Bauer M, Adlercreutz P: Adsorption of lipase on polypropylene powder. Biochim Biophys Acta 1997, 1345:188-196.

doi:10.1186/2043-7129-2-6

Cite this article as: Ayres et al:: Two-step process for preparation of oligosaccharide propionates and acrylates using lipase and Cyclodextrin Glycosyl Transferase (CGTase). Sustainable Chemical Processes 2014 2:6.

\section{Publish with ChemistryCentral and every scientist can read your work free of charge \\ "Open access provides opportunities to our colleagues in other parts of the globe, by allowing anyone to view the content free of charge." \\ W. Jeffery Hurst, The Hershey Company. \\ - available free of charge to the entire scientific community \\ - peer reviewed and published immediately upon acceptance \\ - cited in PubMed and archived on PubMed Central \\ - yours - you keep the copyright \\ Submit your manuscript here: \\ http://www.chemistrycentral.com/manuscript/<smiles>c1ccccc1</smiles> 